\title{
Fox-Fordyce Disease: Dermoscopic Perspective
}

\author{
Archana Singal $^{a}$ Ishmeet Kaur ${ }^{b}$ Deepak Jakhar ${ }^{b}$ \\ aDepartment of Dermatology and STD, University College of Medical Sciences and GTB Hospital, Delhi, India; \\ ${ }^{b}$ Department of Dermatology and STD, North Delhi Municipal Corporation Medical College and Hindu Rao Hospital, \\ Delhi, India
}

\section{Established Facts}

- Fox-Fordyce disease is a rare disease of apocrine sweat glands.

- Diagnosis is usually based on clinical presentation of monomorphic skin-colored follicular papules in apocrine-rich sites like axilla.

\section{Novel Insights}

- Dermoscopy can play an important role in the diagnosis of Fox-Fordyce disease.

- Dermoscopy of Fox-Fordyce disease shows light brown to dark brown structureless areas (lacking any specific pigmentary network) with folliculocentricity and central hyperkeratotic plug. Non-polarizing dermoscopy shows loss of dermatoglyphics over the lesions.

\section{Keywords}

Fox-Fordyce disease · Dermoscopy · Sweat glands · Axilla · USB dermatoscope

\section{Abstract \\ Fox-Fordyce disease (FFD) is a rare chronic skin disease of the apocrine unit. It presents chiefly in postpubertal females as grouped, monomorphic, skin-colored follicular papules as- sociated with intense pruritus commonly in axillae but may involve pubic, perineal, areolar, and umbilical areas [An Bras Dermatol. 2018;93(1):161-2]. Diagnosis is mostly clinical as histological features are often nonspecific and variable. However, the lesions at times may be mistaken for irritant contact dermatitis, lichen nitidus, syringoma, etc. [J Derma-}

tol. 2009;36(9):485-90]. Dermoscopy is being increasingly utilized in pigmentary and inflammatory skin disorders. In this communication, we describe the dermoscopic features in FFD, which shows typical light brown to dark brown folliculocentric structureless areas with loss of dermatoglyphics. Some of the lesions also show hyperkeratotic follicular plugging.

(c) 2020 S. Karger AG, Basel

\section{Case Report}

A 19-year-old girl presented with skin-colored intensely itchy lesions in both axillae of 4 years duration. The lesions were progressive and more symptomatic in summers. There was no history of any topical application/fragrance use. Examination revealed
Prof. Archana Singal

Department of Dermatology and STD

University College of Medical Sciences and GTB Hospital

Street-1, Delhi 110095 (India)

archanasingal@hotmail.com 
Fig. 1. Clinical picture showing multiple follicular skin-colored papules in the axilla.
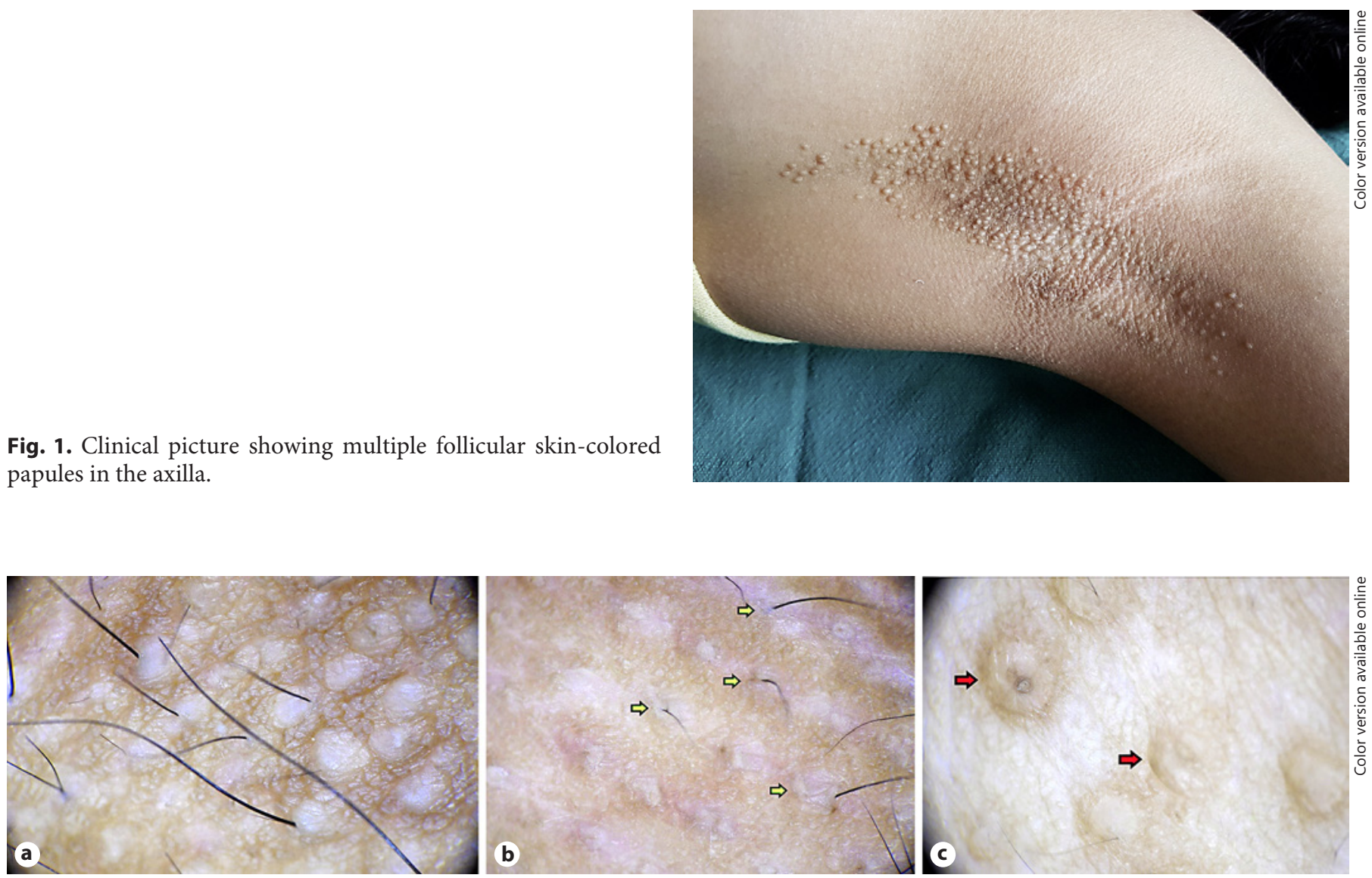

Fig. 2. Dermoscopic analysis: non-polarized dermoscopy ( $\times 10$ magnification $)$ showing loss of dermatoglyphics (a), polarizing dermoscopy ( $\times 10$ magnification) showing multiple follicular light brown to dark brown structureless areas (b), and hyperkeratotic follicular plugging (c).

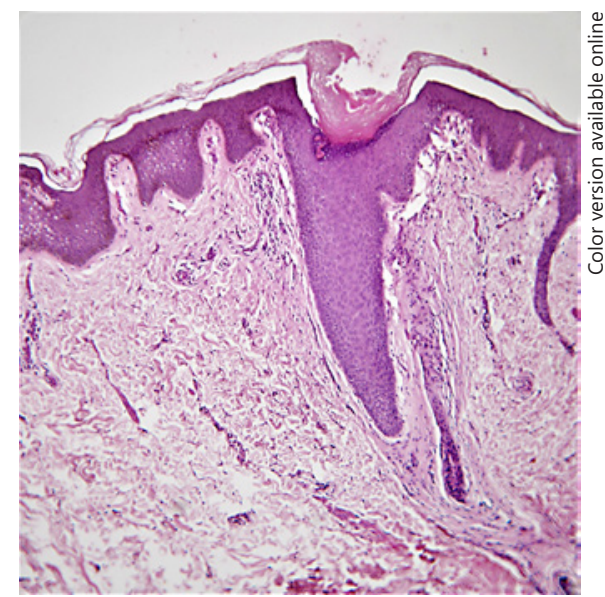

Fig. 3. Histopathology (HE. $\times 40)$ showing dilated follicular infundibulum with keratin plugging along with mononuclear inflammatory infiltrate around the adjacent apocrine ducts. multiple, grouped, soft non-tender pinhead-sized, skin-colored follicular papules in bilateral axilla (Fig. 1). There was no evidence of hyper/hypo/brom/chromhidrosis. Axillary hair density was sparse. No florescence was noted on Wood's lamp examination. Similar lesions were also observed in the bilateral areolar region. There was no lymphadenopathy. Rest of the mucocutaneous, hair, and nail examinations were normal.

Dermoscopic evaluation was done with a hand-held dermatoscope (DermLite 3Gen). Non-polarized mode showed loss of dermatoglyphics over the lesion (Fig. 2a). Polarized mode showed folliculocentric, light brown to dark brown structureless areas (Fig. 2b). Some of the lesions showed hyperkeratotic follicular plugs replacing the hair follicles (Fig. 2c). Histopathology was done from one of the representative papules, which showed the presence of dilated follicular infundibulum with hyperkeratosis with keratin plugging with mononuclear inflammatory infiltrate around the adjacent apocrine ducts along with fibrosis (Fig. 3). Based on clinical, histological and dermoscopic features, a diagnosis of FoxFordyce disease (FFD) was made, and the patient was started on topical retinoids. Significant improvement was observed within 3 months of treatment. 


\section{Discussion}

Dermoscopy in general dermatology has gained popularity in recent past. The utility of dermoscopy in assisting clinical examination of skin disorders is gaining importance. FFD is an uncommon inflammatory condition of apocrine unit with an unclear etiology. It is postulated that due to blockage of apocrine infundibulum by a keratin plug, the duct ruptures, leading to inflammatory infiltrate in the dermis [1-3]. This results in formation of itchy skin-colored papules in apocrine gland-bearing areas like axilla, areola, umbilicus, perineum, and perianal region. The extravasation of glandular content is postulated to be the cause of itching in these lesions $[2,3]$.

The diagnosis of FFD is based on characteristic clinical features and site of the lesions. When diagnosis is in doubt, histopathology may aid and show dilation of follicular infundibulum with hyperkeratosis, acanthosis, and spongiosis of infundibular epithelium and perifollicular lymphocytic infiltrate [2-4]. However, histopathology tends to be nonspecific and may not be feasible in all cases owing to the site of lesions. Dermoscopy is a useful tool in such scenarios. It can aid in differentiating it from other closed differentials such as lichen nitidus, syringoma, etc. Lichen nitidus shows a classic sunburst appearance on dermoscopy [5], while syringoma shows white dots corresponding to the eccrine duct openings [6]. To the best of our knowledge, dermoscopy in FFD has been reported only once previously in a 42 -year-old woman who showed multiple folliculocentric skin - yellowish papules with central hair and blackheads [7]. The follicular hyperkeratotic plugs on dermoscopy correspond to the dilated follicular infundibula with hyper- keratosis on histology [7]. Dermoscopy of Grahm-LittlePiccardi syndrome shows follicular hyperkeratosis and accentuation of follicular ostia [8].

\section{Conclusion}

Dermoscopy shows typical features which correlate well with the clinical and histopathological features in FFD. We recommend the use of dermoscopy in all cases of FFD to establish and standardize the dermoscopic features.

\section{Statement of Ethics}

Written informed consent was obtained from the patient to publish photos and details.

\section{Disclosure Statement}

The authors hereby declare that they have no conflict of interest regarding the work.

\section{Funding Source}

The authors did not receive any funding.

\section{Author Contribution}

All authors have contributed toward writing, research, data analysis, and editing of the manuscript.

\section{References}

1 Miao C, Zhang H, Zhang M, Zhang X. FoxFordyce disease. An Bras Dermatol. 2018; 93(1):161-2.

2 Kao PH, Hsu CK, Lee JY. Clinicopathological study of Fox-Fordyce disease. J Dermatol. 2009;36(9):485-90.

3 Yost J, Robinson M, Meehan SA. Fox-Fordyce disease. Dermatol Online J. 2012;18(12):28.

4 George A, Bhatia A, Thomas E. Fox-Fordyce disease: a report of 2 cases responding to topical clindamycin. Indian J Dermatol Venereol Leprol. 2015;81(1):87-8.
5 Jakhar D, Grover C, Kaur I, Sharma S. Response to "Dermatoscopic features of lichen nitidus”. Pediatr Dermatol. 2018 Nov; 36(1):179-7.

6 Ankad B, Sakhare P, Prabhu M. Dermoscopy of non-melanocytic and pink tumors in brown skin: a descriptive study. Indian J Dermatopathol Diagn Dermatol. 2017 Jul 1; 4(2):41.
7 Blasco-Morente G, Naranjo-Díaz MJ, PérezLópez I, Martínez-López A, Ruiz-Villaverde R, Aneiros-Fernández J. Fox-Fordyce disease. Sultan Qaboos Univ Med J. 2016;16(1):e11920.

8 Steglich RB, Tonoli RE, Pinto GM, Müller FM, Guarenti IM, Duvelius ES. Graham-Little Piccardi Lassueur syndrome: case report. An Bras Dermatol. 2012;87(5):775-7. 